\title{
Bruns nystagmus: an important clinical clue for cerebellopontine angle tumours
}

\author{
Sugata Narayan Biswas, ${ }^{1}$ Sudip Ray, ${ }^{2}$ Somedeb Ball, ${ }^{3}$ Partha Pratim Chakraborty ${ }^{1}$
}

${ }^{1}$ Internal Medicine, Midnapore Medical College and Hospital, Midnapore, West Bengal, India ${ }^{2}$ Paediatrics, Midnapore Medical College and Hospital, Midnapore, West Bengal, India ${ }^{3}$ Internal Medicine, Texas Tech University Health Sciences Center, Lubbock, Texas, USA

\section{Correspondence to} Dr Partha Pratim Chakraborty, docparthapc@yahoo.co.in

Accepted 18 December 2017

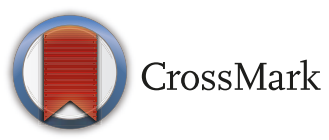

To cite: Biswas SN, Ray S, Ball S, et al. BMJ Case Rep Published Online First: [please include Day Month Year]. doi:10.1136/bcr-2017223378

\section{DESCRIPTION}

A 24-year-old woman presented with gradual-onset left-sided hearing loss, progressive diminution of vision, headache and unsteadiness of gait. Comprehensive clinical evaluation revealed a left-sided lower motor neuron type of facial nerve palsy (figure 1), bilateral papilloedema, sensory loss in the distribution of ophthalmic branch of the left trigeminal nerve and cerebellar ataxia. Sensorineural hearing loss and absent corneal reflex were also observed on the left side. A coarse, left-beating nystagmus with leftward gaze and a fine primary-position rightbeating nystagmus which increased on rightward gaze, consistent with Bruns nystagmus (video 1), were appreciated. In view of the clinical findings, a diagnosis of a space-occupying lesion involving the left cerebellopontine angle was considered. MRI of the brain documented a space-occupying lesion $(4 \times 3.5 \mathrm{~cm})$ in the left cerebellopontine angle, most likely a vestibular schwannoma (figures 2 and 3 ). The condition was explained to the patient and the need for surgical intervention. However, on being informed of the relative inexperience of neurosurgical interventions in such cases at our centre, she chose to attend a different medical facility with a higher surgical expertise, and was subsequently lost

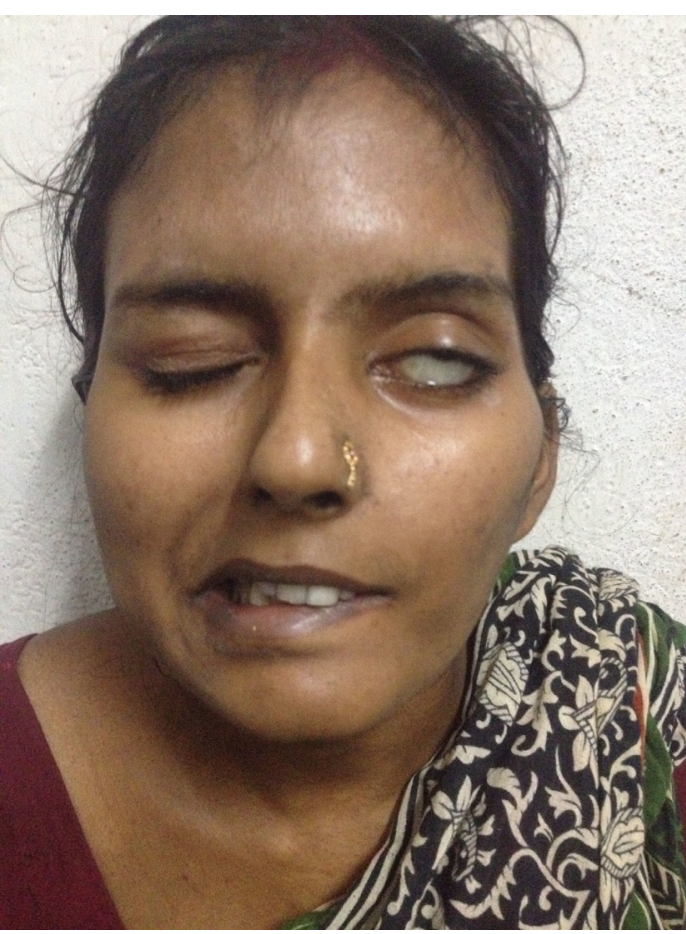

Figure 1 Figure demonstrating a left-sided lower motor neuron type of facial nerve palsy.

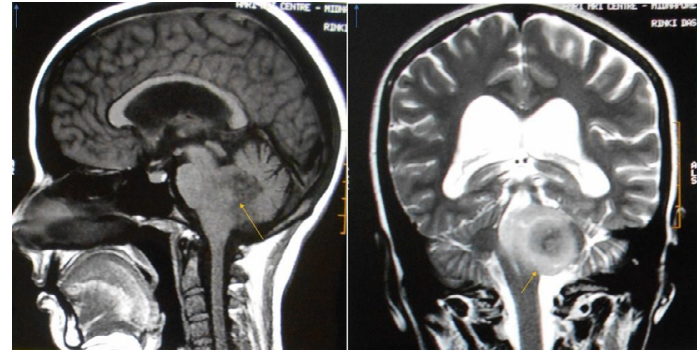

Figure 2 Sagittal T1-weighted (left) and coronal T2-weighted (right) images demonstrating a spaceoccupying lesion in the left cerebellopontine angle compressing the brainstem and vestibulocerebellum.

to follow-up. Bruns nystagmus is usually associated with large tumours of the cerebellopontine angle causing significant brainstem distortion, compression of the flocculus and/or vestibulocerebellum. ${ }^{1}$ In a study conducted on patients with unilateral vestibular schwannoma, the overall prevalence of Bruns nystagmus was estimated to be $11 \%$. With large tumours having maximal diameter greater than $3.5 \mathrm{~cm}$, the prevalence was observed to be higher $(92 \%$ of patients had nystagmus, $67 \%$ of whom had Bruns nystagmus). ${ }^{2}$ It comprises of a coarse, high-amplitude horizontal nystagmus with low oscillatory frequency as the patient looks towards the side of the lesion, but a fine, low-amplitude, high-frequency primary-position nystagmus that increases as the patient looks to the side opposite the lesion. ${ }^{3}$ Bruns nystagmus primarily is a form of jerk nystagmus, characterised by alternating slow and fast components. After focusing an object on the fovea, failure of gaze-holding results in the deviation of the eyes, contributing to the slow component of the nystagmus. Subsequently, corrective saccades, in an effort to refocus the object of interest back on the fovea, contribute to the fast

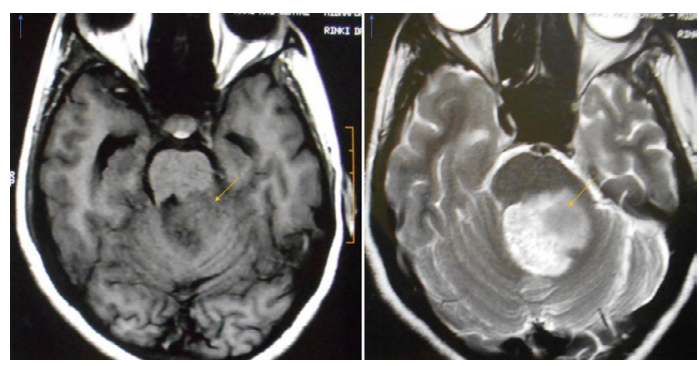

Figure 3 Axial T1-weighted (left) and T2-weighted (right) images demonstrating a space-occupying lesion in the left cerebellopontine angle compressing the brainstem and vestibulocerebellum. 


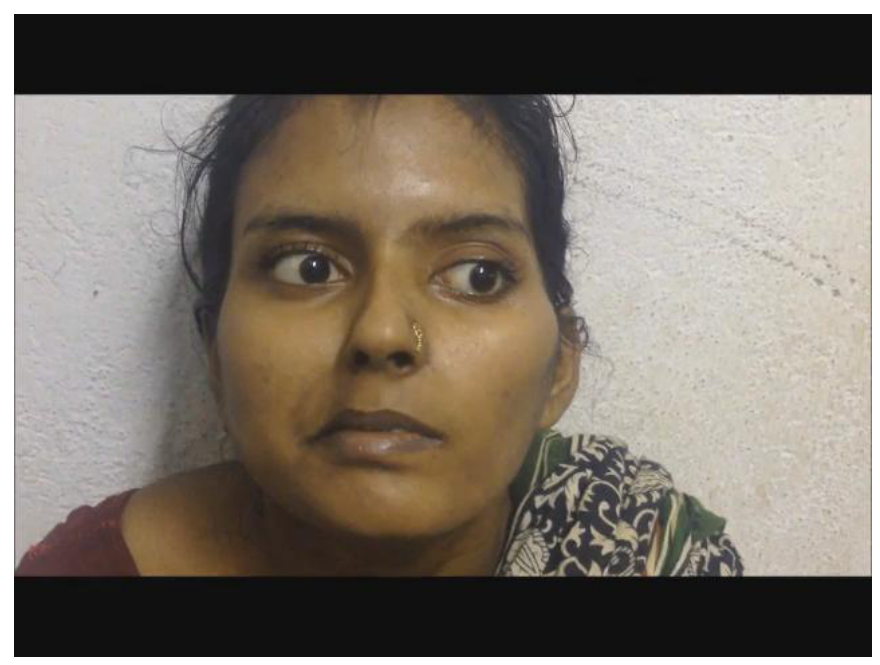

Video 1 Video showing a coarse, high-amplitude horizontal nystagmus with low oscillatory frequency as the patient looks towards the left (side of lesion), but a fine, low-amplitude, high-frequency primary-position nystagmus that increases as the patient looks to the right (side opposite the lesion).

component of the nystagmus. However, in Bruns nystagmus, the pathophysiology involves simultaneous impairment of different neural networks. Compression of the ipsilateral pons leads to a dysfunctional neural integrator (also the flocculus), which is unable to maintain eccentric gaze towards the side of the lesion, resulting in a high-amplitude, low-frequency, gaze paretic nystagmus. ${ }^{3}$ On the other hand, vestibular dysfunction leads to decreased tonic firing, which results in a slow-phase movement towards the side of the lesion with a compensatory fast-beating component in the contralateral direction. ${ }^{3}$ Knowledge of this rare variant of bidirectional nystagmus is important as it aids in making a prompt clinical diagnosis of cerebellopontine angle

\section{Learning points}

- Bruns nystagmus, a rare variant of bidirectional nystagmus, has an important localising property as it aids in the diagnosis of cerebellopontine angle tumours.

- Bruns nystagmus comprises a coarse, horizontal nystagmus with low oscillatory frequency as the patient looks towards the side of the lesion, but a fine, high-frequency primaryposition nystagmus that increases as the patient looks to the side opposite the lesion.

- The underlying pathophysiology involves simultaneous impairment of different neural networks (flocculus and vestibular involvement).

tumours. Bruns nystagmus, rarely, has also been reported in pontine stroke and cerebellar apoplexy. ${ }^{4}$

Contributors SNB and PPC were involved in the diagnosis and management of the patient. SNB, SR and SB were involved in literature search and manuscript preparation. PPC was involved in reviewing and critical input. All four were involved in finalising the article.

Competing interests None declared.

\section{Patient consent Obtained.}

Provenance and peer review Not commissioned; externally peer reviewed.

(C) BMJ Publishing Group Ltd (unless otherwise stated in the text of the article) 2018. All rights reserved. No commercial use is permitted unless otherwise expressly granted.

\section{REFERENCES}

1 Croxson GR, Moffat DA, Baguley D. Bruns bidirectional nystagmus in cerebellopontine angle tumours. Clin Otolaryngol Allied Sci 1988;13:153-7.

2 Lloyd SK, Baguley DM, Butler K, et al. Bruns' nystagmus in patients with vestibular schwannoma. Otol Neurotol 2009;30:625-8.

3 Venkateswaran R, Gupta R, Swaminathan RP. Bruns nystagmus in cerebellopontine angle tumor. JAMA Neurol 2013;70:646.

4 Chen JJ, Li WH, Hsieh KY, et al. Bruns-cushing nystagmus due to hypertensive unilateral paramedian pontine base infarction. Am J Emerg Med 2012;30:1326.e5-1326.e7.

Copyright 2017 BMJ Publishing Group. All rights reserved. For permission to reuse any of this content visit

http://group.bmj.com/group/rights-licensing/permissions.

BMJ Case Report Fellows may re-use this article for personal use and teaching without any further permission.

Become a Fellow of BMJ Case Reports today and you can:

- Submit as many cases as you like

- Enjoy fast sympathetic peer review and rapid publication of accepted articles

- Access all the published articles

- Re-use any of the published material for personal use and teaching without further permission

For information on Institutional Fellowships contact consortiasales@bmjgroup.com

Visit casereports.bmj.com for more articles like this and to become a Fellow 